\title{
Proposição de diretrizes estratégicas para elevar o conceito da pós-graduação: estudo de caso do PPGGEO
}

\section{Strategic guidelines for a proposal to elevate the graduate concept: a case study of the PPGGEO}

\section{Propuesta de directrices estratégicas para incrementar el concepto de postgrado: estudio de caso del PPGGEO}

http://dx.doi.org/10.21713/2358-2332.2016.v13.903

Amanda Antonello Giuliani, Mestre em Gestão Estratégica de Organizações pela Universidade Regional Integrada do Alto Uruguai e das Missões (URI) e docente do curso de Administração da URI, São Luiz Gonzaga, RS, Brasil. E-mail: amandagiuliani@yahoo. com.br.

Rut Maria Friedrich Marquetto, Doutora em Desenvolvimento Regional pela Universidade de Santa Cruz do Sul (Unisc) e docente do Programa de Pós-Graduação em Mestrado de Gestão Estratégica de Organizações (PPGGEO) e do curso de graduação em Administração, na Universidade Regional Integrada do Alto Uruguai e das Missões (URI), Santo Ângelo, RS, Brasil. E-mail:rutmarquetto@gmail.com.

João Serafim Tusi da Silveira, Doutor em Engenharia da Produção (UFSC) dfe docente do Programa de Pós-Graduação em Mestrado de Gestão Estratégica de Organizações (PPGGEO) na Universidade Regional Integrada do Alto Uruguai e das Missões (URI), Santo Ângelo, RS. E-mail:joaotusi@hotmail.com.

Vilmar Antônio Boff, Doutor em Desenvolvimento Regional pela Universidade de Santa Cruz do Sul (Unisc) e docente titular da Universidade Estadual do Rio Grande do Sul (Uergs), Cruz Alta, RS, Brasil.E-mail:vaboff@gmail.com. 
Lucas Veiga Ávila, Doutorando em Administração na Universidade Federal de Santa Maria (UFSM) e docente assistente da Universidade Estadual do Rio Grande do Sul (Uergs), Frederico Westphalen, RS, Brasil. E-mail: admlucasveiga@gmail.com.

\section{Resumo}

Este artigo apresenta uma proposta de diretrizes para que o Programa de Pós-Graduação em Gestão Estratégica de Organizações (PPGGEO), Mestrado Profissional, da Universidade Regional Integrada do Alto Uruguai e das Missões (URI), campus Santo Ângelo, RS, alcance maior conceito na avaliação da Coordenação de Aperfeiçoamento de Pessoal de Nivel Superior (Capes) que será realizada em 2016. Caracteriza-se como pesquisa qualitativa, sendo descritiva e exploratória, pois a formulação da proposta de diretrizes fundamenta-se em leitura de autores e organismos que tratam do tema, bem como na ficha de avaliação aplicada ao PPGGEO pela Capes no ano de 2013.

Palavras-chave: Estratégia Organizacional. Programas de PósGraduação Stricto Sensu. PPGGEO. Avaliação Capes.

\section{Abstract}

This article presents a proposal for guidelines for the Graduate Program in the Strategic Management of Organizations (PPGGEO), Professional Masters of the Integrated Regional University of Upper Uruguay and the Missions (URI), campus St. Angelo, RS. It seeks to provide an expanded concept of the evaluation of the Brazilian Federal Agency for Support and Evaluation of Graduate Education (CAPES) to be held in 2016. The study is characterized as qualitative research that is descriptive and exploratory, since the formulation of the proposed guidelines is based on the reading of authors and entities dealing with the theme, as well as on the evaluation form applied to the PPGGEO by Capes in 2013.

Keywords: Organizational Strategy. Post-Graduate Study Programs. PPGGEO. Capes Evaluation. 


\section{Resumen}

En este artículo se presenta una propuesta de directrices para que el Programa de Postgrado en Gestión Estratégica de Organizaciones (PPGGEO), Maestría Profesional, de la Universidad Regional Integrada del Alto Uruguay y de las Misiones (URI), campus de Santo Ângelo, RS, alcance concepto más amplio en la evaluación de la Coordinación de Perfeccionamiento de Personal de Nivel Superior (Capes) que tendrá lugar en 2016. Se caracteriza como investigación cualitativa, siendo descriptiva y exploratoria, ya que la formulación de la propuesta de directrices se basa en la lectura de autores y órganos que tratan del tema, así como en el formulario de evaluación aplicado a PPGGEO por Capes en 2013.

Palabras clave: Programas de Estrategia Organizacional. Programas de Postgrado Strictu Sensu. PPGGEO. Evaluación Capes.

\section{INTRODUÇÃO}

Para analisar a gestão estratégica de uma organização torna-se necessário conhecer a filosofia institucional, pois ela é um componente do planejamento estratégico que pode revelar muito sobre a organização e sua forma de gestão, evidenciando a missão, a visão e os valores que nortearão seus objetivos, interesses e ações. A partir da missão, a ação organizacional pode ser canalizada para um conjunto de objetivos e metas estratégicas que orientarão seus rumos na direção de sua visão estratégica de futuro. A visão de futuro, por sua vez, expressa o pensamento estratégico da organização em busca de seus horizontes de longo prazo (ÁVILA, 2014).

As universidades são um tipo peculiar de organização que, em tempos recentes, vêm sendo instadas a promover seu desenvolvimento, tomando por base um processo planejado que torne explícito o seu pensamento estratégico, ancorado em missão e visão claramente definidas, além de diretrizes norteadoras, aliando suas ações no ensino, na pesquisa e na extensão. 
Neste mesmo sentido, grandes organizações se diferenciam das demais no que tange aos seus esforços para construir diferentes sistemas, primando pela melhoria contínua de seus processos. Quando se observa o ambiente acadêmico, não é diferente, uma vez que se evidencia um crescimento exponencial de instituições de ensino superior (IES) que vêm adotando em seus programas de ensino cursos de pósgraduação stricto sensu nas modalidades de mestrado acadêmico, mestrado profissional e doutorado. Os processos e estratégias de desenvolvimento das instituições de ensino superior em nível de pósgraduação stricto sensu devem ser planejados de modo eficiente e efetivo, com a melhor concentração de esforços.

A Universidade Regional Integrada do Alto Uruguai e das Missões - Campus Santo Ângelo conta com três programas de pós-graduação em nivel stricto sensu: o mestrado em Direito, o Mestrado Profissional em Ensino Científico e Tecnológico e o Mestrado Profissional em Gestão Estratégica de Organizações (PPGGEO). O PPGGEO iniciou suas atividades em 2011 e passou pelo seu último processo de avaliação pela Coordenação de Aperfeiçoamento de Pessoal de Nível Superior em 2013, referente aos anos de 2011 e 2012. Atualmente, o programa busca qualificar seu conceito, visando obter maiores benefícios, como aumento e qualificação do seu corpo docente, melhores recursos para projetos, aumento do seu quadro discente, bolsas de estudos e, principalmente, a abertura do curso de doutorado.

Tendo em vista o fato de que o curso atingiu a nota 3 e percebendose a cada vez mais acirrada concorrência entre as instituições de ensino superior, a prevalência de alunos mais exigentes e uma maior fiscalização por parte dos organismos públicos, surgiu a seguinte questão: o que pode ser feito no PPGGEO para elevar o conceito de 3 para 4, tornando-o mais competitivo no mercado em face das exigências impostas pela Capes?

Diante do exposto, o presente estudo tem como objetivo analisar estratégias e propor diretrizes ao PPGEO para que este alcance um conceito mais elevado na próxima avaliação da Capes. 


\section{INSTITUICÕES DE ENSINO SUPERIOR - IES}

As organizações que prestam serviços de ensino superior no Brasil são chamadas de instituições de ensino superior (IES) e podem ser públicas ou privadas. As instituições públicas de ensino são aquelas sustentadas pelo poder público nas esferas federal, estadual e municipal. Já as IES privadas são dirigidas por pessoas físicas ou jurídicas de Direito Privado, sem ou com finalidade de lucro. As instituições privadas sem finalidade de lucro são: a) as comunitárias, que incluem em sua entidade mantenedora representantes da comunidade; b) as confessionais, que atendem a determinada orientação confessional e ideológica; e c) as filantrópicas, que prestam serviços à população em caráter complementar às atividades do Estado, como dispõe a Lei de Diretrizes e Bases da Educação, em seu art. 20 (BRASIL, 1996).

No que diz respeito à classificação acadêmico-administrativa, as IES podem receber diferentes denominações. As IES, quando credenciadas pelo Ministério da Educação (MEC), podem ser chamadas de faculdades, centros universitários e universidades (BRASIL, 2014). Ainda segundo o MEC (2014), inicialmente a IES é credenciada como faculdade. O credenciamento como universidade ou centro universitário, com as respectivas prerrogativas de autonomia, depende do credenciamento específico da instituição já credenciada, em funcionamento regular e com padrão satisfatório de qualidade. O primeiro credenciamento da instituição tem prazo máximo de três anos para faculdades e centros universitários, e de cinco anos para as universidades.

Cada IES possui características que Ihes são pertinentes, conforme mostra o quadro a seguir. 


\section{Quadro 1 - Descrição das instituições de ensino superior}

\begin{tabular}{|l|l|}
\hline Denominação & \multicolumn{1}{c|}{ Características } \\
\hline Faculdade & $\begin{array}{l}\text { A faculdade tem duas conotações. A primeira é a de uma } \\
\text { instituição de ensino superior que não apresenta autonomia } \\
\text { para conferir títulos e diplomas, os quais devem ser registrados } \\
\text { por uma universidade. Além disso, não tem a função de } \\
\text { promover a pós-graduação. O segundo sentido é aplicado para } \\
\text { se referir a unidades orgânicas de uma universidade. }\end{array}$ \\
\hline Centro universitário & $\begin{array}{l}\text { O centro universitário é instituição pluricurricular, que abrange } \\
\text { uma ou mais áreas do conhecimento. É semelhante à } \\
\text { universidade em termos de estrutura, mas não está definido } \\
\text { na Lei de Diretrizes e Bases da Educação e não apresenta o } \\
\text { requisito da pesquisa institucionalizada. }\end{array}$ \\
\hline Universidade & $\begin{array}{l}\text { A universidade é uma instituição acadêmica pluridisciplinar } \\
\text { que conta com produção intelectual institucionalizada, além } \\
\text { de apresentar requisitos mínimos de titulação acadêmica (um } \\
\text { terço de mestres e doutores) e carga de trabalho do corpo } \\
\text { docente (um terço em regime integral). É autônoma para criar } \\
\text { cursos e sedes acadêmicas e administrativas, expedir diplomas, } \\
\text { fixar currículos e número de vagas, firmar contratos, acordos } \\
\text { e convênios, entre outras ações, respeitadas as legislações } \\
\text { vigentes e a norma constitucional. }\end{array}$ \\
\hline
\end{tabular}

Fonte: elaboração dos autores com base no Portal Brasil (2014).

Cabe ainda relatar que existem os institutos federais de educação, ciência e tecnologia e os centros federais de educação tecnológica, que também são considerados instituições de ensino superior pelo MEC.

Conforme o MEC (2014), as IES podem oferecer diferentes cursos, tais como:

- Graduação - cursos superiores que conferem diplomas nos graus de bacharelado, licenciatura ou tecnologia e são abertos a candidatos que tenham concluído o ensino médio ou equivalente e sido classificados em processo seletivo;

- Pós-graduação stricto sensu - cursos de educação superior compreendendo os programas de mestrado e doutorado acadêmico ou profissional, que conferem diploma aos concluintes. Os cursos de pós-graduação stricto sensu são sujeitos às exigências de autorização, reconhecimento e renovação de reconhecimento;

- Especialização ou pós-graduação lato sensu - programas abertos a candidatos diplomados em cursos de graduação e que atendam às exigências das instituições de ensino, observada a carga horária mínima e os requisitos fixados nas normas próprias, e conferem 
certificados aos concluintes. Os cursos de especialização em nível de pós-graduação lato sensu presenciais (nos quais se incluem os cursos designados como MBA - Master Business Administration) oferecidos por instituições de ensino superior independem de autorização, reconhecimento e renovação de reconhecimento. Os cursos de pósgraduação lato sensu a distância podem ser ofertados por instituições de educação superior, desde que possuam credenciamento para educação a distância;

- Residência médica - programa de pós-graduação lato sensu, especialização na área médica, caracterizado como treinamento em serviço;

- Residência multiprofissional em saúde - programa de pósgraduação lato sensu, especialização nas áreas de saúde distintas da Medicina caracterizadas como treinamento em serviço;

- Extensão - programa de formação da educação superior voltado a estreitar a relação entre universidade e sociedade, aberto a candidatos que atendam aos requisitos estabelecidos pelas instituições de ensino e que confere certificado aos estudantes concluintes. Compreende programas, projetos e cursos voltados a disseminar para o público externo o conhecimento desenvolvido e sistematizado nos âmbitos do ensino e da pesquisa e, reciprocamente, compreender as demandas da comunidade relacionadas às competências acadêmicas da instituição de educação superior.

Como se percebe, existe um número muito expressivo de instituições de ensino superior, com suas particularidades, oferecendo e disponibilizando no mercado diversos cursos para qualificação do corpo discente. Este estudo se voltará para os programas de pós-graduação stricto sensu, mestrado profissional.

\section{MESTRADO PROFISSIONAL}

Diferentemente do mestrado acadêmico, que é mais voltado ao ensino e à pesquisa, o mestrado profissional ${ }^{1}$, segundo a Portaria Normativa do MEC n 17, de 28 de dezembro de 2009, art. 3ㄹ é “uma modalidade de pós-graduação stricto sensu que possibilita”, entre

O reconhecimento dos mestrados profissionais pela Capes foi feito pela Portaria $\mathrm{n}^{\circ}$ 080, de 16 de dezembro de 1998 (CAPES, 
outras coisas, "a capacitação de pessoal para a prática profissional avançada e transformadora de procedimentos e processos aplicados, por meio da incorporação do método científico, habilitando o profissional para atuar em atividades técnico-científicas e de inovação" (BRASIL, 2009).

Para a Capes (2014), o objetivo do mestrado profissional é contribuir com o setor produtivo nacional no sentido de agregar um nível maior de competitividade e de produtividade a empresas e organizações, sejam elas públicas ou privadas.

Ainda de acordo com a Capes (2014),

[...] as propostas de cursos novos na modalidade Mestrado Profissional devem apresentar uma estrutura curricular que enfatize a articulação entre conhecimento atualizado, domínio da metodologia pertinente e aplicação orientada para o campo de atuação profissional específico. Para isto, uma parcela do quadro docente deve ser constituída de profissionais reconhecidos em suas áreas de conhecimento por sua qualificação e atuação destacada em campo pertinente ao da proposta do curso. 0 trabalho final do curso deve ser sempre vinculado a problemas reais da área de atuação do profissional-aluno e de acordo com a natureza da área e a finalidade do curso, podendo ser apresentado em diversos formatos.

O mestrado profissional deve, assim como os demais cursos stricto sensu, ser acompanhado e avaliado por comissões especializadas com base em critérios predeterminados e definidos de acordo com cada programa. Embora seja uma política recente no Brasil, programas como o Mestrado Profissional em Administração Pública da Escola Brasileira de Administração Pública (Ebape), que foi lançado em 2014 com o alcance da nota 4, detinha uma estrutura que possibilitava a oferta de turmas regulares e intensivas de intercâmbios internacionais de curta e média duração, nos quais, como estratégia de internacionalização e posicionamento no ambiente global, seus alunos podiam cursar disciplinas equivalentes em outros MPs sem custos adicionais na mensalidade (EBAPE, 2015).

Nesse sentido, para garantir a qualidade dos mestrados profissionais, critérios operacionais e normas foram delineados e 
considerados necessários para dirigir e controlar sua implantação e desenvolvimento. A autorização, o reconhecimento e a renovação de reconhecimento dos cursos de mestrado profissional são obtidos a partir dos resultados do acompanhamento e da avaliação conduzidos pela Capes, de acordo com as exigências previstas em legislação.

\section{A AVALIAÇÃO DOS CURSOS DE PÓS-GRADUAÇÃO STRICTO SENSU}

Todos os cursos de pós-graduação stricto sensu, para que consigam se manter e oferecer ensino de qualidade, devem passar pelo crivo da avaliação. No Brasil, a Coordenação de Aperfeiçoamento de Pessoal de Nivel Superior é o órgão do Ministério da Educação responsável pelo reconhecimento e pela avaliação de cursos de pósgraduação stricto sensu (mestrado profissional, mestrado acadêmico e doutorado) em âmbito nacional.

De acordo com a Capes (2014), os objetivos da avaliação são:

- Certificação da qualidade da pós-graduação brasileira (referência para a distribuição de bolsas e recursos para o fomento à pesquisa);

- Identificação de assimetrias regionais e de áreas estratégicas do conhecimento no sistema nacional de pós-graduação para orientar ações de indução na criação e expansão de programas de pós-graduação no território nacional.

Também segundo a Capes (2014), há dois processos distintos que se referem à avaliação: o de avaliação das propostas de novos cursos e o de avaliação periódica dos cursos em andamento.

A avaliação é realizada em 48 áreas, número vigente em 2014, e segue uma mesma sistemática e conjunto de quesitos básicos estabelecidos no Conselho Técnico Científico da Educação Superior (CTC-ES). Ainda,

Os documentos de área são referência para os processos avaliativos, tanto na elaboração e submissão de propostas de cursos novos quanto na avaliação trienal dos cursos em funcionamento. Neles estão descritos o estado atual, as características e as perspectivas, assim como os quesitos considerados prioritários na avaliação dos programas de pós-graduação 
pertencentes a cada uma das 48 áreas de avaliação. Em conjunto com as Fichas de Avaliação e os Relatórios de Avaliação, os Documentos de Área constituem o trinômio que expressa os processos e os resultados da Avaliação Trienal (Capes, 2014).

A Capes ainda acompanha o desempenho dos cursos em andamento ao longo do intervalo entre as avaliações. Dessa maneira, as instituições fornecem informações regularmente e on-line por meio do módulo Coleta de Dados, na Plataforma Sucupira. Após essa etapa ocorre o tratamento das informações pelo corpo técnico da Capes e, em seguida, é feita a análise pelas comissões de consultores especialistas, que emitem pareceres e notas para cada programa e relatórios para o conjunto dos programas da área. Os pareceres são analisados, e, após isso, os relatores apresentam pareceres conclusivos. Por fim, ocorre a deliberação, quando há a aprovação e o reconhecimento dos cursos (Capes, 2014). Esse processo pode ser visualizado na Figura 1.

\section{Figura 1 - Processo de avaliação do mestrado profissional, mestrado acadêmico e doutorado da Capes}

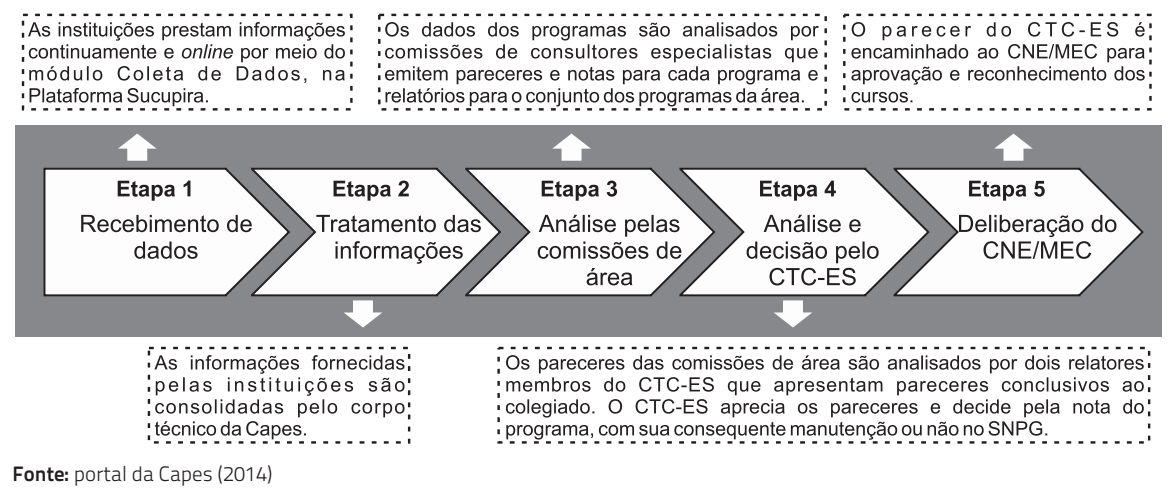

Em conformidade com a Capes (2015), todo o processo de avaliação é realizada por consultores especializados das distintas áreas do conhecimento atuantes no magistério superior e na pesquisa. 
que oferecem apenas cursos de mestrado podem obter, no máximo, nota 5; os programas que receberem notas 1 e 2 deixam de ser recomendados pela Capes; os resultados das avaliações de todos os programas são encaminhados ao Conselho Técnico Científico da Educação Superior - CTC-ES, da Capes e ao Conselho Nacional de Educação - CNE, para homologação e, em seguida, ao Ministro de Estado da Educação para o ato de reconhecimento que é necessariamente publicado no Diário Oficial (CAPES, 2015).

Ainda de acordo com a Capes (2014), os cinco grandes eixos de avaliação são: proposta do programa; corpo docente; corpo discente, teses e dissertações; produção intelectual, e inserção social. As avaliações desses eixos estão descritas nos respectivos documentos de área. Mas, a cada nova avaliação, em razão dos aprendizados de cada processo, esses cinco eixos são atualizados, modificados e aprimorados. O FOPROF (2011) elaborou um relatório propositivo para a avaliação e a sustentabilidade dos MPs, contribuindo para o avanço das reflexões, a exemplo da construção de critérios específicos no que se refere: à ficha de avaliação; à elaboração do Qualis Tecnológico; às métricas para o quesito "inserção social”; ao doutorado profissional; à formação de um banco de avaliadores de MPs e um projeto de lei instituindo um modelo de financiamento do MP, sinalizando algumas conquistas por meio de seus grupos de trabalho.

Na ficha de avaliação da Capes, cada eixo de avaliação é subdividido em outros itens de avaliação. São determinadas notas que possuem um peso específico, bem como uma avaliação gradual: "não aplicável”, "deficiente", "fraco", "regular", "bom” e "muito bom”.

Os responsáveis pelos cursos devem estar atentos, observando os eixos e suas subdivisões de avaliação, com o intuito de os manterem e melhorarem suas notas.

Como se observa, os programas são avaliados, sobretudo, com base nos professores, nos alunos, nas teses e nas dissertações produção intelectual. Além disso, na avaliação, também são relevantes quesitos como a inserção social e diferenciais de alta qualificação e desempenho. Para Sander (apud PAIXÃO et al., 2014), é pertinente que, 
após o término do curso, seja realizada a análise do trabalho de conclusão de curso e, por dois anos, acompanhado o destino dos egressos, para mensurar seu valor agregado, identificando a capacidade do aluno de intervir positivamente no ambiente de trabalho, o que reflete a qualidade dos MPs. Paixão et al. (2014) e também o Fórum Nacional dos Mestrados Profissionais (FOPROF, 2011) discutem a criação de indicadores de avaliação específicos para os MPs uma vez que essa modalidade de curso tem características peculiares.

Na avaliação de 2013, para a grande área de Ciências Sociais Aplicadas do Brasil, a Capes ajuizou 97 cursos (17,1\% do total na área) e, destes, 71,1\% obtiveram conceito 3 e apenas 9,3\% ficaram com 5 (FOPROF, 2013).

Salienta-se que as avaliações, que eram trienais até 2013, passaram a ser realizadas a cada quatro anos. De acordo com as informações da Capes (2014), a primeira avaliação quadrienal está prevista para ser realizada em julho de 2017, versando sobre dados e informações de 2013 a 2016. Ainda de acordo com a Capes (2015), foi aprovada a proposta de realização, no meio do período quadrienal, de uma análise que aponte tendências dos programas de pós-graduação.

\section{MÉTODO DO ESTUDO}

O presente estudo caracteriza-se como qualitativo (DENZIN; LINCOLN, 2006). A pesquisa qualitativa apresenta as seguintes características essenciais: tem o ambiente natural como fonte direta de dados; tem o pesquisador como instrumento fundamental de coleta de dados; utiliza procedimentos descritivos da realidade estudada; busca o significado das situações para as pessoas e os efeitos sobre a sua vida; preocupa-se com o processo e não simplesmente com os resultados e com o produto, e privilegia o enfoque indutivo na análise dos dados (BOGDAN; BIKLEN, 1994).

Segundo Gil (1999), a pesquisa caracteriza-se como exploratória e descritiva. A pesquisa exploratória procura desenvolver, esclarecer e modificar conceitos e ideias com o intuito de formular problemas mais 
precisos para estudos posteriores, e a pesquisa descritiva descobre e observa fenômenos, na tentativa de descrevê-los, classificá-los e interpretá-los, sem, no entanto, ter o compromisso de explicá-los, embora sirva de base para a explicação (VIEIRA, 2005).

Quanto ao sujeito da pesquisa, foi selecionado o PPGGEO classificando-se um estudo de caso único, denominado o caso do PPGGEO, que, segundo Yin (2010), se mostra adequado, pois tem sua conveniência atribuída aos fatores comuns nos casos selecionados.

Para a coleta de evidências, foi elaborado um único protocolo, composto de categorias; para observação direta na entrevista, observação dos documentos do programa e de documentos e relatórios da Capes. Para a condução da entrevista, em especial, foram considerados alguns aspectos (GIL, 1999), tais como: preparação do roteiro, estabelecimento do contato inicial, formulação das perguntas, estímulo a respostas completas, registro das respostas e conclusão da entrevista. Posteriormente, foi realizado o levantamento de dados em duas fases (HAIR et al., 2005).

Na primeira fase de coleta, inicialmente, foram selecionados os dados primários e secundários obtidos em documentos, na legislação, no site e em publicações da universidade e em relatório da Capes, entre outros. Cabe destacar que, no uso de múltiplas fontes de evidências, foi necessária a criação de uma base de dados, estudando posteriormente cada documento, para que, logo após, fosse realizado um encadeamento das evidências. Na segunda fase, foi realizada entrevista com representante da coordenação do PPGGEO, o qual vislumbrou clarificação das ações propostas em documentos, bem como aprendizado do funcionamento do programa e anseios estratégicos.

Para a interpretação dos dados, adotou-se a análise de conteúdo, tendo em vista o contorno que a investigação assumiu, e esta pode ser definida como um conjunto de técnicas de análise, visando obter procedimentos sistemáticos e objetivos das ações e estratégias para o planejamento das universidades (BARDIN, 2009). 
Os temas recorrentes foram agrupados segundo suas semelhanças e significados, dando-se, assim, ênfase às principais evidências para cada categoria. Desse modo, buscou-se interpretar a problemática da pesquisa à luz da teoria revisada e a partir da valorização da fala dos entrevistados e dos documentos observados, por meio da técnica de triangulação. (PATTON, 2002).

Na seção dos resultados, apresentar-se-á uma descrição sintética sobre o cenário do PPGGEO, bem como seu processo de planejamento, as características da gestão universitária, a legislação, a abrangência acadêmica, o ensino, a pesquisa, a extensão, a gestão e suas similaridades para o crescimento do programa. Será também apresentada a avaliação do PPGGEO referente aos anos de 2011 e 2012 e feita a proposição de diretrizes para o programa, o corpo docente e o corpo discente.

\section{APRESENTAÇÃO DOS RESULTADOS}

Neste item apresentam-se as atividades realizadas de acordo com o objetivo do estudo.

\subsection{Caracterização da instituição}

O presente estudo tem como objeto o Programa de PósGraduação Stricto Sensu em Gestão Estratégica de Organizações (PPGGEO) Mestrado Profissional, da Universidade Regional Integrada do Alto Uruguai e das Missões (URI), Campus Santo Ângelo. O PPGGEO está vinculado à área de Ciências Sociais Aplicadas e se destina à formação continuada para o desenvolvimento de técnicas modernas, ao aperfeiçoamento e à qualificação de profissionais, tendo em vista a necessidade de aprofundar conteúdos adquiridos na graduação. Conforme seu regimento, ele contribui para tornar mais amplo e integrado o campo de conhecimento dos profissionais, devido às transformações do mundo corporativo (URI, 2014). 
O PPGGEO tem como objetivo geral:

Estabelecer um equilíbrio entre o mundo acadêmico e as estratégias organizacionais, interagindo com o setor público e privado, na geração e difusão de conhecimentos relevantes, buscando através da produção científica, soluções que facilitem o processo de desenvolvimento regional, de forma sustentável (URI, 2014).

O PPGGEO foi reconhecido por meio da Portaria do MEC n 1.325, de 21 de setembro de 2011, publicada no Diário Oficia/ de 22 de setembro de 2011 e é recomendado pela Capes desde então (BRASIL, 2014). O PPGGEO conta em seu quadro funcional com: duas secretárias, 14 docentes permanentes e cinco docentes colaboradores. Atualmente, são 39 os mestrandos, ingressos nos anos 2011 a 2014.

\subsection{Avaliação do PPGGEO - anos 2011 e 2012}

Com base na ficha de avaliação da Capes, o PPGGEO obteve na sua última avaliação, em 2013, tendo os anos de 2011 e 2012 como base para a coleta de dados, o conceito 3.

O quadro a seguir, de forma adaptada da ficha de avaliação do PPGGEO pela Capes, mostra os eixos e os itens de avaliação com as respectivas notas.

Quadro 2 - Ficha de avaliação do PPGGEO pela Capes - avaliação 2013

\begin{tabular}{|l|l|c|}
\hline \multicolumn{1}{|c|}{ Eixo } & \multicolumn{1}{|c|}{ Itens de avaliação } & Conceito \\
\hline $\begin{array}{l}\text { 1. Proposta } \\
\text { do programa }\end{array}$ & $\begin{array}{l}\text { 1.1 Coerência, consistência, abrangência eatualização } \\
\text { da(s) área(s) de concentração, linha(s) de atuação, } \\
\text { projetos em andamento, proposta curricular com os } \\
\text { objetivos do programa. }\end{array}$ & Fraco \\
\cline { 2 - 3 } & $\begin{array}{l}\text { 1.2 Coerência, consistência e abrangência dos } \\
\text { mecanismos de interação efetiva com outras } \\
\text { instituições, atendendo a demandas sociais, } \\
\text { organizacionais ou profissionais. }\end{array}$ & Regular \\
\cline { 2 - 3 } & $\begin{array}{l}\text { 1.3 Infraestrutura para ensino, pesquisa e } \\
\text { administração. }\end{array}$ & Bom \\
\cline { 2 - 3 } & $\begin{array}{l}\text { 1.4 Planejamento do programa visando ao } \\
\text { atendimento de demandas atuais ou futuras de } \\
\text { desenvolvimento nacional, regional ou local, por meio } \\
\text { da formação de profissionais capacitados para a } \\
\text { solução de problemas e práticas deforma inovadora. }\end{array}$ & Regular \\
\hline
\end{tabular}




\begin{tabular}{|c|c|c|}
\hline Eixo & Itens de avaliação & Conceito \\
\hline \multirow[t]{3}{*}{$\begin{array}{l}\text { 2.Corpo } \\
\text { docente }\end{array}$} & $\begin{array}{l}\text { 2.1 Perfil do corpo docente, considerando experiência } \\
\text { como pesquisador e/ou profissional, titulação e sua } \\
\text { adequação à proposta do programa. }\end{array}$ & Regular \\
\hline & $\begin{array}{l}\text { 2.2 Adequação da dimensão, composição e dedicação } \\
\text { dos docentes permanentes para o desenvolvimento } \\
\text { das atividades de pesquisa e formação do programa. }\end{array}$ & Muito bom \\
\hline & $\begin{array}{l}\text { 2.3 Distribuição das atividades de pesquisa, projetos } \\
\text { de desenvolvimento e inovação e de formação entre } \\
\text { os docentes do programa. }\end{array}$ & Fraco \\
\hline \multirow[t]{3}{*}{$\begin{array}{l}\text { 3. Corpo } \\
\text { discente e } \\
\text { trabalhos de } \\
\text { conclusão }\end{array}$} & $\begin{array}{l}\text { 3.1 Quantidade de trabalhos de conclusão (MP) } \\
\text { aprovados no período e sua distribuição em relação } \\
\text { ao corpo discente titulado e ao corpo docente do } \\
\text { programa. }\end{array}$ & Não aplicável \\
\hline & $\begin{array}{l}\text { 3.2 Qualidade dos trabalhos de conclusão produzidos } \\
\text { por discentes e egressos. }\end{array}$ & Não aplicável \\
\hline & 3.3 Aplicabilidade dos trabalhos produzidos. & Não aplicável \\
\hline \multirow[t]{4}{*}{$\begin{array}{l}\text { 4. Produção } \\
\text { Intelectual }\end{array}$} & $\begin{array}{l}\text { 4.1 Publicações qualificadas do programa por docente } \\
\text { permanente. }\end{array}$ & Deficiente \\
\hline & $\begin{array}{l}\text { 4.2 Produção artística, técnica, patentes, inovações e } \\
\text { outras produções consideradas relevantes. }\end{array}$ & Deficiente \\
\hline & $\begin{array}{l}\text { 4.3 Distribuição da produção científica e técnica ou } \\
\text { artística em relação ao corpo docente permanente } \\
\text { do programa. }\end{array}$ & Deficiente \\
\hline & $\begin{array}{l}\text { 4.4 Articulação da produção artística, técnica e } \\
\text { científica entre si e com a proposta do programa. }\end{array}$ & Regular \\
\hline \multirow{4}{*}{$\begin{array}{l}\text { 5. Inserção } \\
\text { social }\end{array}$} & 5.1 Impacto do programa. & Bom \\
\hline & $\begin{array}{l}5.2 \text { Integração e cooperação com outros cursos / } \\
\text { programas com vistas ao desenvolvimento da pós- } \\
\text { graduação. }\end{array}$ & Deficiente \\
\hline & $\begin{array}{l}5.3 \text { Integração e cooperação com organizações } \\
\text { e/ou instituições setoriais relacionadas à área } \\
\text { de conhecimento do programa, com vistas ao } \\
\text { desenvolvimento de novas soluções, práticas, } \\
\text { produtos ou serviços nos ambientes profissional e/ } \\
\text { ou acadêmico. }\end{array}$ & Bom \\
\hline & $\begin{array}{l}5.4 \text { Divulgação e transparência das atividades e da } \\
\text { atuação do programa. }\end{array}$ & Bom \\
\hline
\end{tabular}

Fonte: elaboração dos autores com base na ficha, 2014.

Após a avaliação de cada eixo e item realizado em 2013, foi descrita a justificativa concebida pela comissão da Capes, cujos componentes eram consultores externos de diversas universidades, faculdades e institutos do país, pela conceituação das notas. 
No eixo 1, Proposta do programa, a comissão julgou regular. A apreciação foi no sentido de que as linhas em que o programa atua deveriam ser mais harmoniosas para expor a produção do conhecimento científico; que a proposta é pouco aplicada no programa e que os projetos de pesquisas tratam de temas que precariamente refletem a linha de atuação "estratégias organizacionais". Também foi descrito que os projetos e pesquisas não possuem intercambio com outras IES, embora envolvam algumas organizações locais e regionais. Em relação à infraestrutura do programa, de acordo com a avaliação, foi compatível com o seu tamanho, incluindo número suficiente de salas, equipamentos multimídia, apoio didático, internet, climatização e mobiliário. A avaliação deixou explícita ainda que o programa necessita apresentar normas mais claras de credenciamento e de descredenciamento de docentes permanentes e de docentes que colaboram com o programa.

No eixo 2, Corpo docente, a comissão julgou regular. A análise foi a de que a experiência acadêmica dos professores está razoavelmente alinhada à proposta de formação discente para um programa novo e que esta não apresenta dados suficientes sobre a experiência profissional. 0 lado bom é que não existe dependência dos colaboradores, as disciplinas e atividades, projetos e orientações são executados pelos docentes permanentes, e, destes, 75\% participam das atividades de ensino (em 2012), o que está aquém da métrica esperada de envolvimento com aula.

No eixo 3, Corpo discente e trabalhos de conclusão, a comissão avaliou como não aplicável. A alegação foi a de que o programa iniciou suas atividades em 2011 e inexistiam trabalhos de conclusão para serem avaliados.

No eixo 4, Produção intelectual, a comissão julgou fraco. A crítica foi a de que a produção científica pelos docentes é incipiente, bem como a de que a produção técnica dos docentes permanentes é rudimentare está concentrada em dois docentes permanentes. A produção técnica/ tecnológica possui uma leve harmonia entre si e com a proposta do programa.

No eixo 5, Inserção social, a comissão atribuiu o conceito regular. A comissão destacou como bom em sua apreciação o impacto e potencial 
do programa nas dimensões educacional, social e econômica no âmbito local. Destacaram-se as atividades que estavam sendo realizadas na região, porém relatou-se a falta de integração com outras instituições de ensino superior. Por outro lado, foram consideradas a boa integração e a cooperação com organizações públicas e privadas e também associações profissionais nos contextos local e regional. Foi observado que o programa possui um sitena Internet, que mantém os dados sobre o programa atualizados, sendo de fácil manipulação e acesso, tanto pelo site da universidade como por meio de mecanismos de buscas.

Em relação à qualidade dos dados, a comissão atribuiu o conceito regular para o programa, outorgando a nota 3. Segundo a apreciação, as linhas de atuação poderiam ser mais sólidas para expressar a especificidade da produção do conhecimento científico desenvolvido no contexto do programa. Embora o corpo docente cumpra os requisitos preconizados quanto à titulação, à formação, à estabilidade e à dedicação ao programa, há necessidade de adequação na distribuição das atividades dos professores permanentes no que tange à coordenação de projetos de pesquisa e desenvolvimento técnico e tecnológico e à produção intelectual. Menos de $25 \%$ dos professores estão envolvidos com tais atividades. Foi novamente destacado o impacto do ponto de vista educacional, social, tecnológico e econômico que o programa tem em âmbito local e região.

Fica claro, diante das considerações relatadas e que foram explanadas na ficha de avaliação do PPGGEO pela Capes, que o curso precisa do esforço e da dedicação de todos os envolvidos no processo coordenação, professores, alunos, colaboradores - para que sejam todos os itens mais bem estimados na próxima avaliação pela Capes.

\subsection{Proposição de diretrizes para elevar o conceito do PPGGEO perante a Capes}

O processo de proposição de diretrizes para elevar ao nível 40 conceito do PPGGEO perante a Capes deu-se com a compilação de várias informações, principalmente daquelas focadas na ficha de avaliação da 
Capes, ano de 2013. Apresentam-se as proposições de diretrizes que a instituição, os docentes e os discentes do PPGGEO poderão avaliar e seguir.

\subsubsection{Proposição de diretrizes ao programa}

A partir da apreciação apresentada pela Capes ao programa, recomenda-se a adoção das seguintes diretrizes:

a. Revisar se as duas linhas de atuação do programa "Desenvolvimento e organização social" e "Estratégias organizacionais" estão de acordo com o preconizado pelo programa, para que consigam expressar de forma mais clara a produção do conhecimento;

b. Atentar para a aceitação de projetos de pesquisa que estejam de acordo com as duas linhas de pesquisa, principalmente em relação à linha "Estratégias organizacionais";

c. Promover intercâmbios de pesquisa e extensão entre institutos de ensino superior em âmbitos local, regional, estadual, federal e internacional;

d. Criar convênios com empresas e instituições locais e regionais que tenham interesse em desenvolver projetos e pesquisas focadas nas linhas do programa;

e. Ampliar o número de artigos que precisam ser publicados pelo corpo discente, para que estes consigam defender seu projeto de pesquisa;

f. Criar um sistema on-line específico, porém de acesso e controle interno somente disponivel para coordenadores, docentes, colaboradores e alunos, que viabilize a inserção, a apresentação, a situação atual e a disponibilidade de todas as atividades, produções e projetos de pesquisa desenvolvidos por cada professor e seus alunos, de maneira a promover a interação e a colaboração entre seus participantes. Isso poderá melhorar o controle dos trabalhos que estão sendo desenvolvidos de acordo com as linhas de pesquisa do programa. O sistema de informação deve apresentar, em imagens gráficas e coloridas, a situação de cada trabalho. Por exemplo: vermelho - início das atividades; amarelo - meio das atividades, e verde - conclusão do trabalho; 
g. Manter e ampliar os fluxos de comunicações, de modo a estimular a interação entre programa, corpo docente e corpo discente;

h. Além do site do programa, estabelecer um canal permanente de comunicação entre o programa e a comunidade local e regional, seja por meio da criação de boletim informativo em jornais e revistas de grande circulação, para a divulgação dos trabalhos desenvolvidos pelo programa e recebimento de comentários, seja por intermédio da realização de seminários em instituições de ensino superior ou outros órgãos parceiros, tais como o Serviço de Apoio às Micro e Pequenas Empresas do Estado do Rio Grande do Sul (SEBRAE), Conselho Regional de Administração do Rio Grande do Sul (CRA-RS), Conselho Regional de Desenvolvimento do Rio Grande do Sul- Missões (Corede Missões) e governo municipal;

i. Valorizar ações que criem um ambiente de criatividade, inovação, cooperação, integração e participação de todos os envolvidos no programa, como, por exemplo, a formulação de convite para socializarem seus trabalhos com os graduandos de cursos afins ao tema do trabalho a ser apresentado;

j. Promover uma gestão baseada em princípios de qualidade total, focada no cliente (discentes e egressos), estruturada por processos e fundamentada na avaliação e na consecução de resultados.

\subsubsection{Proposição de diretrizes ao corpo docente}

A partir da posição apresentada pela Capes quanto ao programa, recomendam-se as seguintes diretrizes:

a. Incentivar, por meio de recompensa a ser definida posteriormente, que o corpo docente produza no mínimo uma publicação qualificada por semestre em periódicos e revistas com conceito acima de B e compatíveis com as linhas de pesquisa proposta pelo programa;

b. De acordo com cada linha de pesquisa, desenvolver grupos de trabalho entre os professores permanentes e colaboradores para que consigam realizar no mínimo uma produção artística, 
técnica, patente, inovação ou outra produção considerada relevante e afinada com as linhas de proposta do programa;

c. Cada professor, em sua disciplina, requisitar aos seus alunos um artigo para ser avaliado com temática pertinente às linhas de pesquisa propostas pelo programa;

d. Estimular o corpo discente a participar efetivamente de grupos de trabalho, estudo e pesquisa, com o intuito de colaborar para que o programa atinja os requisitos mínimos para elevar seu nível de avaliação.

\subsubsection{Proposição de diretrizes ao corpo discente}

Com base na crítica apresentada pela Capes ao programa, recomendam-se as seguintes diretrizes:

a. Desenvolver pelo menos um artigo em cada disciplina;

b. Encaminhar artigos para serem publicados em revistas e periódicos bem conceituados em âmbitos nacional e internacional;

c. Focar seus estudos no projeto de pesquisa para garantir sua conclusão dentro do prazo estipulado pelo programa;

d. Identificar, junto ao corpo docente de cada disciplina, novas oportunidades de pesquisa;

e. Criar grupos de trabalho para que sejam desenvolvidas ações de integração com outras instituições de ensino superior;

f. Integrar-se ao corpo docente para planejamento e execução de atividades de difusão e troca de experiências com outras instituições de ensino superior, tais como encontros, palestras, seminários, cursos, feiras, mostras etc.;

g. Participar efetivamente de eventos acadêmicos que permitam a troca de conhecimento entre os participantes.

\section{CONSIDERAÇÕES FINAIS}

Buscou-se, neste trabalho, apresentar uma proposta de diretrizes para que PPGGEO consiga aumentar seu conceito na avaliação da Capes, prevista para 2017. Ao final do processo de análise do referencial teórico 
e da análise da ficha de avaliação do PPGGEO elaborada pela Capes, conseguiu-se descrever as proposições para que o programa consiga aumentar seu conceito para 4.

Na realização do estudo, percebeu-se a importância que tem para qualquer programa de pós-graduação stricto sensuatentar para os critérios de avaliação da Capes, no sentido de ajustar-se e aprimorar-se para que possa conquistar conceitos mais elevados e, assim, oferecer aprendizagem de alta qualidade.

Estima-se que, se o PPGGEO conquistar as proposições de diretrizes apresentadas neste trabalho, terá maior probabilidade de elevar para 4 o conceito do curso na próxima avaliação a ser realizada pela Capes.

\section{Referências}

ÁVILA, L. V. A perspectiva da sustentabilidade no plano de desenvolvimento institucional: um estudo das instituições federais de ensino superior. 2014. 126 f. Dissertação (Mestrado em Administração, Linha de Pesquisa de Estratégia, Inovação e Sustentabilidade) - Universidade Federal de Santa Maria, Rio Grande do Sul, 2014. Disponível em: <http://www. sigmees.com/files/A_PERSPECTIVA_DA_SUSTENTABILIDADE_NO_ PLANO.pdf>. Acesso em: 17 ago. 2015.

BARDIN, L. Análise de conteúdo. Lisboa: Edições 70, 1977.

BOGDAN, R.; BIKLEN, S. Investigação qualitativa em educação. Porto: Porto Editora, 1994.

BRASIL. Ministério das relações exteriores. Divisão de temas educacionais. Denominações das Instituições de Ensino Superior. Disponivel em: <http://www.dce.mre.gov.br/nomenclatura_cursos. html>. Acesso em: 11 set. 2014.

Ministério da Educação. Portaria $n^{\circ}$ 1.325, de 21 de setembro de 2011. Diário Oficial [da] República Federativa do Brasil, Poder 
Executivo, Brasília, DF, 22 set. 2011. Seção 1, p. 634. Disponivel em: <http://www.urisan.tche.br/admin/upload/Portaria-Reconhecimentomestrado_1325_09_11.pdf >.. Acesso em: 10 set. 2014.

. Lei n 9.394, de 20 de dezembro de 1996. Estabelece as Diretrizes e Bases da Educação Nacional. Diário Oficial [da] República Federativa do Brasil, Brasília, DF, v. 134, n. 248, 23 dez. 1996. Seção 1, p. 27.834-27.841.

Ministério da Educação. Instituições Credenciadas. 2014. Disponivel em: <http://portal.mec.gov.br/index.php?option=com_ content\&view=article\&id=12467\&ltemid=783>. Acesso em: 26 ago. 2014.

Portaria Normativa $\mathbf{n}^{\circ}$ 17. Disponivel em: $<$ http://www.unb.br/ administracao/decanatos/dpp/legislacao/Portaria\%20Normativa\%20 MEC\%2017\%20-\%20mestrado\%20profissional.pdf $\geq$. Acesso em: 1 set. 2014.

CAPES - Coordenação de Aperfeiçoamento de Pessoal de Nivel Superior. Avaliação da Capes. 2014a. Disponivel em: <http://www.capes. gov.br/36-noticias/4026-entrevista-com-livio-amaral-diretor-deavaliacao-da-capes $\geq$. Acesso em: 26 ago. 2014.

. Avaliação trienal (Mestrado Profissional, Mestrado Acadêmico e

Doutorado). 2015. Disponível em: <http://www.capes.gov.br/avaliacao/ permanencia-no-snpg-avaliacao>. Acesso em: 4 ago. 2015.

Comunicado da Capes - período de avaliação do SNPG. 2014. Disponivel em: < http://www.capes.gov.br/component/content/ article/36-salaimprensa/noticias/7278-comunicado-capes-periodode-avaliacao-do-snpg>. Acesso em: 27 jul. 2016.

Mestrado profissional: o que é? 2014b. Disponivel em: <http://www.capes.gov.br/avaliacao/sobre-a-avaliacao/mestradoprofissional-o-que-e>. Acesso em: 26 ago. 2014.

Portaria $\mathbf{N}^{\circ}$ 080, de 16 de dezembro de 1998. Dispõe sobre o reconhecimento dos mestrados profissionais e dá outras providências. 2016. Disponível em: <https://www.capes.gov.br/images/stories/ 
download/avaliacao/avaliacao-n/1892015-Portaria-CAPES-080-1998. pdf>. Acesso em: 27 maio 2016.

Sobre a avaliação da Capes. 2014c. Disponível em: <http:/ / www. capes.gov.br/36-noticias/6689-resultados-da-avaliacao-da-capesrevelam-que-pos-graduacao-teve-crescimento-de-23-no-trienio $\geq$. Acesso em: 26 ago. 2014.

Sobre a avaliação de Cursos. 2015. Disponível em: < http:/ / capes. gov.br/acessoainformacao/perguntas-frequentes/avaliacao-da-posgraduacao/7421-sobre-avaliacao-de-cursos>. Acesso em: 27 jul. 2016.

Sobre a trienal. 2014. Disponivel em: < http://www. avaliacaotrienal2013.capes.gov.br/home-page/sobre-a-trienal>. Acesso em: 27 jul. 2016.

DENZIN, N. K.; LINCOLN, Y. S. Introdução: a disciplina e a prática da pesquisa qualitativa. In: DENZIN, N. K.; LINCOLN, Y. S. (Orgs.). 0 planejamento da pesquisa qualitativa: teorias e abordagens. 2. ed. Porto Alegre: Artmed, 2006.

EBAPE - Escola Brasileira de Administração Pública e de Empresas. Mestrado Profissional em Administração Pública. 2015. Disponível em: <ebape.fgv.br/node/800>. Acesso em: 30 set. 2015.

FOPROF - Fórum Nacional dos Mestrados Profissionais. Estatísticas dos MPs por áreas - Públicas X Particulares e Conceitos. 2013. Disponível em: <www.foprof.org.br/download/foprof-estatisticas-mps-areaspub-x-part-e-conceitos.pdf>. Acesso em: 10 maio 2016.

Mestrado Profissional: reflexões e proposições para sua avaliação e sustentabilidade. 2011. Disponível em: <www.forpof.org. br/download/reflexoes.pdf>. Acesso em: 10 maio 2016.

GIL, A. C. Métodos e técnicas de pesquisa social. 5. ed. São Paulo: Atlas, 1999. 
HAIR JR., J. F. et al. Fundamentos de métodos de pesquisa em administração. Porto Alegre: Bookman, 2005.

MEC - Ministério da Educação. Parecer do Conselho Nacional de Educação 364/2002. Disponivel em:<portal.mec.gov.br/dmdocuments/ parece_cne_0081_sesu.pdf>. Acesso em: 10 maio 2016.

PAIXÃO, R. B.; BRUNI, A. L.; BECKER, J. L.; TENÓRIO, R. M. Avaliação de Mestrados Profissionais: construção e análise de indicadores à luz da multidimensionalidade. Ensaio: aval. pol. públ. Educ., Rio de Janeiro, v.22, n. 83, p. 505-532, abr./jun. 2014. Disponivel em: <http://www.scielo.br/ pdf/ensaio/v22n83/a10v22n83.pdf>. Acesso em: 8 maio 2016.

PATTON, M. Q. Qualitative evaluation and research methods. 2 ed. Newbury Park: Sage, 2002.

URI Universidade Regional Integrada do Alto Uruguai e das Missões. Mestrado em Gestão Estratégica de Organizações - Mastering in organizationstrategic management. Disponivel em: <http://www. santoangelo.uri.br/mestradogestao/\#>. Acesso em: 26 ago. 2014.

VIEIRA, M. M. F. Por uma boa pesquisa (qualitativa) em Administração. In: VIEIRA, M. M. F.; ZOUAIN, D. M. (Orgs.). Pesquisa Qualitativa em Administração. Rio de Janeiro: FGV, 2005.

YIN, R. K. Estudo de caso: planejamento e métodos. 4. ed. Porto Alegre: Bookman, 2010.

Recebido em 24/02/2016 Aprovado em 18/05/2016 